\title{
Fotografía y desaparición. Tres series fotográficas en torno a los 119
}

Photography and disappearance. Three photographical series on the 119

\section{CRISTIÁN KIRBY · cristiankirby@gmail.com}

Entre los años 1991-1995 realiza estudios de Sociología en la Universidad de Humanismo Cristiano y entre 1995-1997, estudios de Cine con la especialidad en fotografía cinematográfica en la Escuela de Cine de Chile. En sus propuestas fotográficas incluye el uso de procedimientos fotosensibles sobre soportes no tradicionales y edición digital.

Considera fundamental en su trabajo las particularidades ontológicas del medio, como es la indicialidad del referente y sus repercusiones, estéticas, formales, conceptuales y experimentales, las que ve enfrentadas en su estrategia visual al re-conocimiento de la realidad.

Desde el 2009 se dedica de forma exclusiva a desarrollar proyectos fotográficos personales y expone sistemáticamente de forma individual como colectiva, en museos e instituciones de Chile como del extranjero (Uruguay, Argentina, Brasil, Colombia, Francia, España, Alemania, China, Bolivia, Venezuela, Berlín). Pueden consultarse sus trabajos en su web.

DOI: 10.7203/KAM.6.6932

ISSN: 2340-1869

Presentamos tres series fotográficas en torno a los 119 desparecidos del Plan Colombo. La primera de ellas, 'Lugares de desaparición', registra los lugares en los que fueron detenidos o vistos por última vez, tensionando los espacios de la ciudad actual con la carga de su ausencia y su vacío. La segunda de ellas, '119', consiste en 119 fotoemulsiones en las que los rostros de los desaparecidos han sido proyectado sobre el plano de las calles de Santiago, revelando fracturas, agujeros y vacíos en los rostros que son las fracturas, agujeros y vacíos del sentido social tras la desaparición. La tercera, 'Verdrangung/Reforest', documenta y explora el proyecto de reforestación de un espacio rural llevado a cabo por el colectivo de familiares de los 119. 


\section{9 agujeros negros en Santiago Christian PeÑaloZa Castillo}

Un agujero negro es, en términos nada especialistas, el encuentro siniestro del tiempo y del espacio en un cronotopo del universo. Nada escapa a él: allí donde/cuando ocurre, hasta la luz es absorbida por su implacable fuerza. Solo cierta radiación logra escapar y hacer que el tiempo siga hacia

adelante. Un haz de luz, radioactiva en este caso, logra establecer un marco de esperanza al tiempo y al espacio.

En 1975, la dictadura militar de Pinochet hizo desaparecer a 119 personas, la mayoría integrantes del MIR, en lo que se conoció como el Plan Colombo. La operación contemplaba un plan internacional, para convencer a la opinión pública nacional de que, en realidad, estas 119 personas habían escapado al extranjero y que fuera de nuestros límites se mataban entre ellos (de ahí el dantesco titular de $L a$ Segunda "Exterminan como ratas a miristas"). En realidad, los 119 estaban, en esos momentos, sufriendo torturas en los distintos centros creados para tales efectos por la dictadura militar y son detenidos desaparecidos hasta el día de hoy. Por supuesto, el juicio que busca esclarecer lo sucedido duerme en tribunales.

El fotógrafo Cristian Kirby ha recogido el eco de silencio y oscuridad permanente de estas 119 desapariciones. Su preocupación son los lugares en que por última vez se vio con vida o se supo de la existencia de cada una de estas 119 personas. Es, entonces, no solo una preocupación ética por estos desaparecidos; es también una preocupación ética por la ciudad. Porque estos lugares son, en definitiva, 119 agujeros negros que nadie ve, que nadie conoce, pero que están ahí, en nuestros barrios, en nuestras calles, en nuestros recorridos. Son cronotopos siniestros de absorción de luz.

Son 119 fotografías crudas en su tratamiento de la luz y de la composición. También son crudas en su narrativa: espacios vacíos, desolados, difíciles de reconocer y de situar en nuestra santiaguina actualidad. No parecen imágenes del Santiago del 2012, más bien parecen retratos macabros del segundo inmediatamente posterior al secuestro de la luz, del tiempo y de la historia de esos 119 chilenos. Parecen el registro del temblor silencioso de lo recién ocurrido, del momento exactamente siguiente en que se consumó la ausencia. Ausencia que perdura hasta hoy, aunque todos esos espacios los llenemos día a día de bulla, de movimiento y de pasmosa normalidad.

Kirby ha preparado, además, el plano triste de estas 119 desapariciones. En este plano, Santiago se evidencia como una ciudad construida, en sus últimos 35 años, sobre la huella invisible y dolorosa del terrorismo de Estado y de la indolencia civil. No hay lugar de la gran ciudad en que un agujero negro no se haya producido, ni en su norte, ni en su sur, ni en su oriente ni en su poniente. El resultado es simplemente desolador. 


\section{Lugares de desaparición}

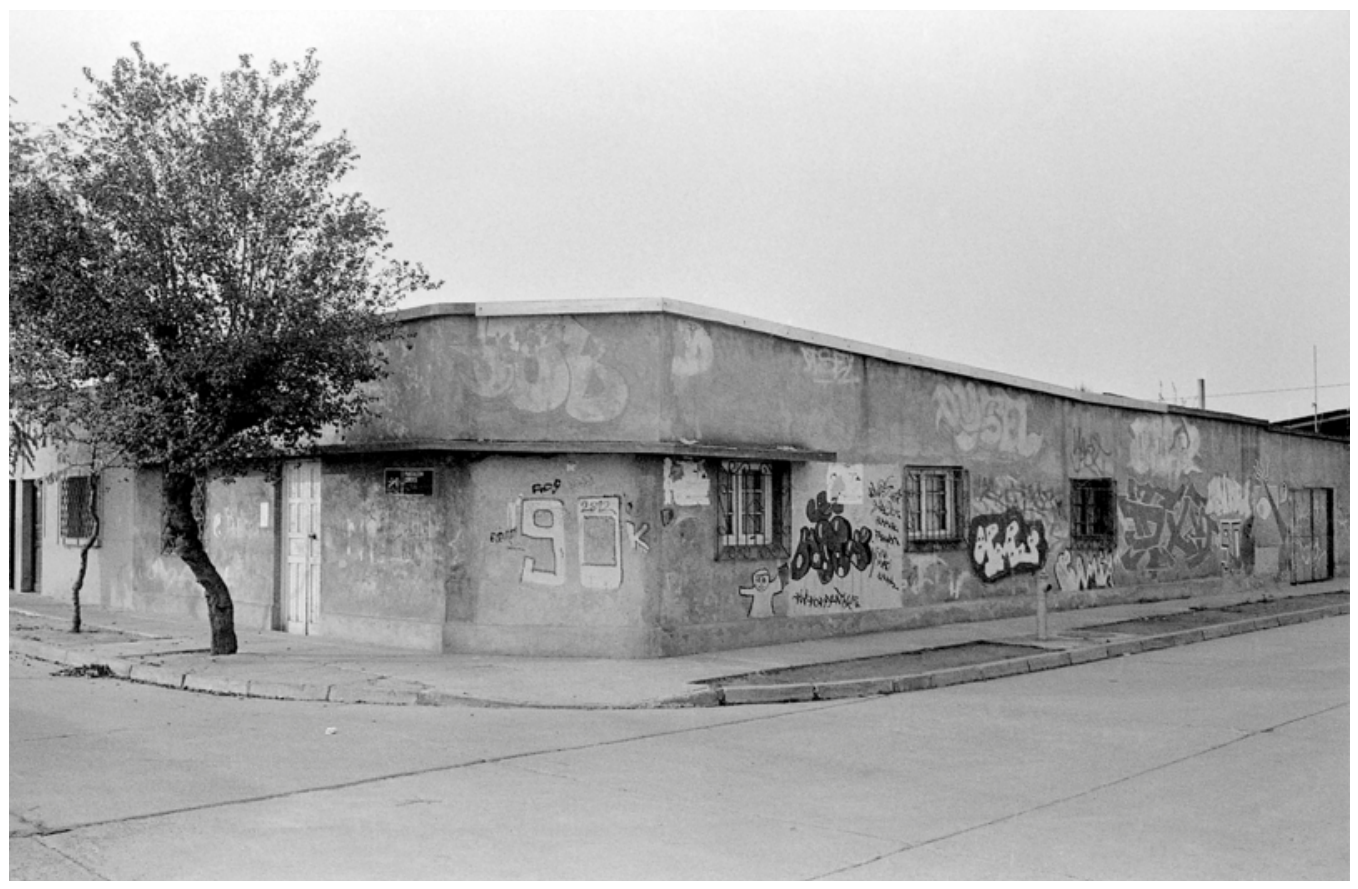

Ismael Darío Chavéz Lobos. Los copihues, 1977. Quinta Normal.

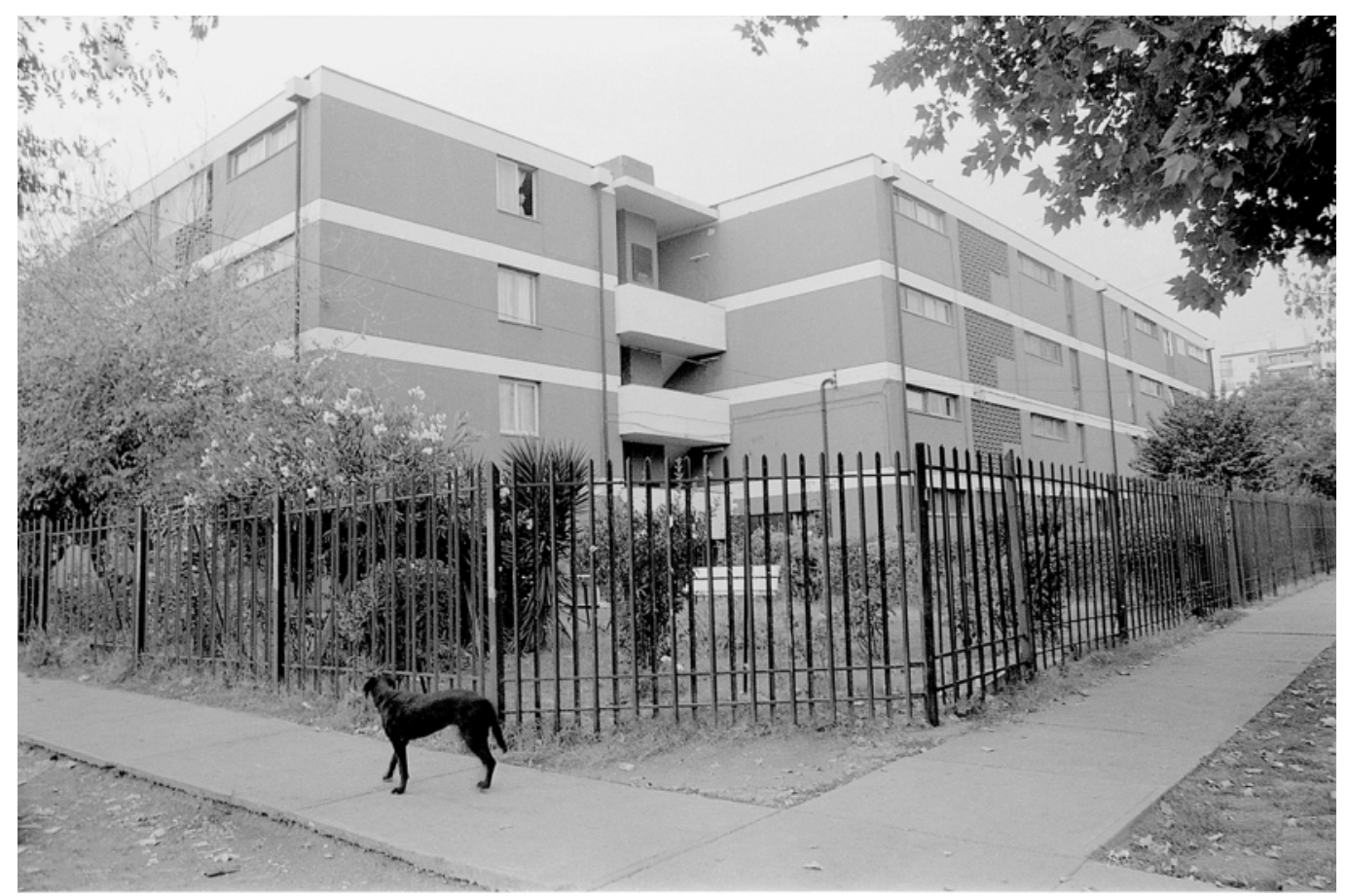

Héctor Marcial Garay Hermosilla. Los aromos 2720. Depto 31.

AVATARES DEL TESTIMONIO EN AMÉRICA LATINA

KAMCHATKA 6 DICIEMBRE 2015. PÁGS. 785-797 


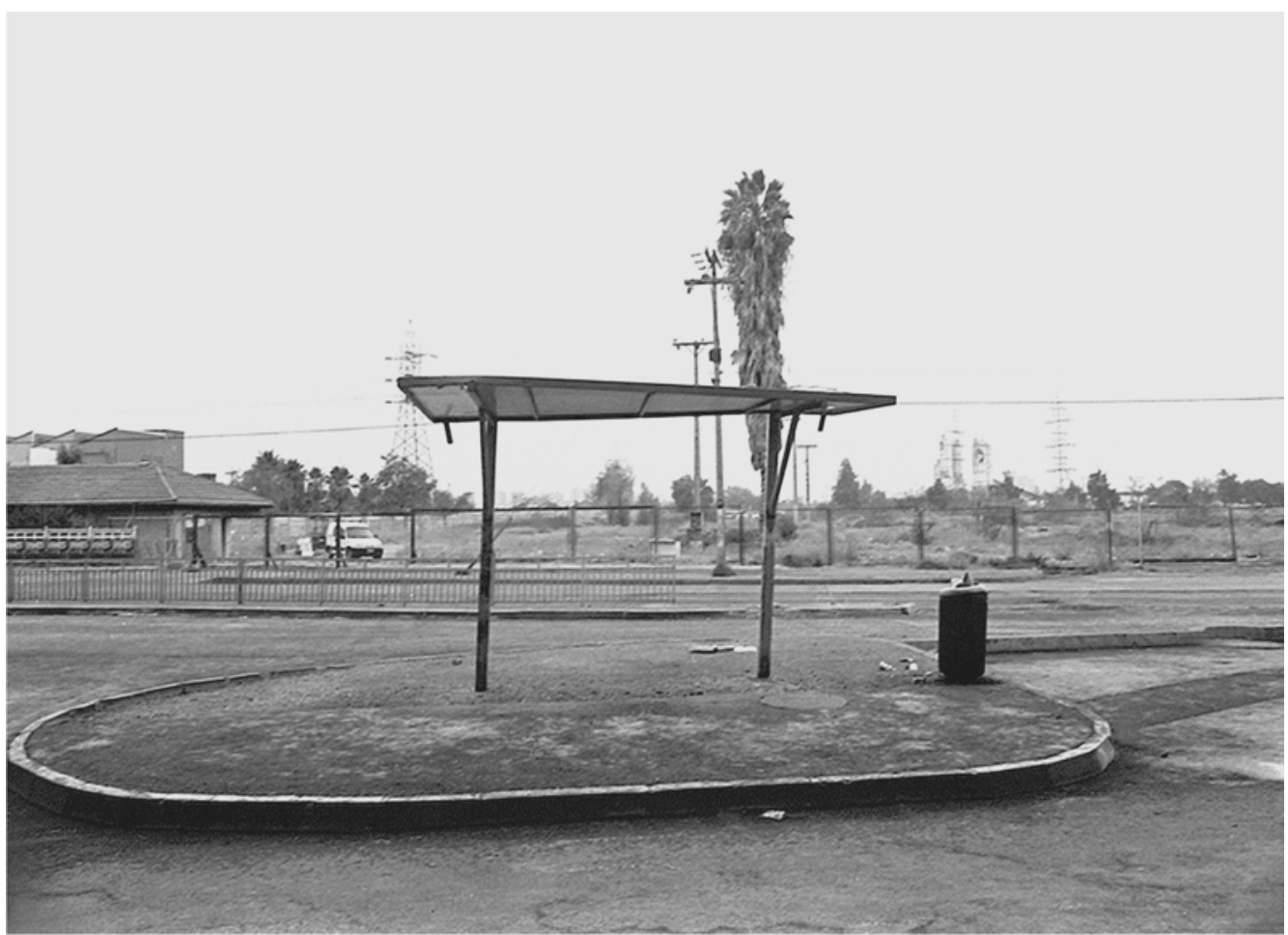

Carlos Valdovinos. Vicuña Mackenna.

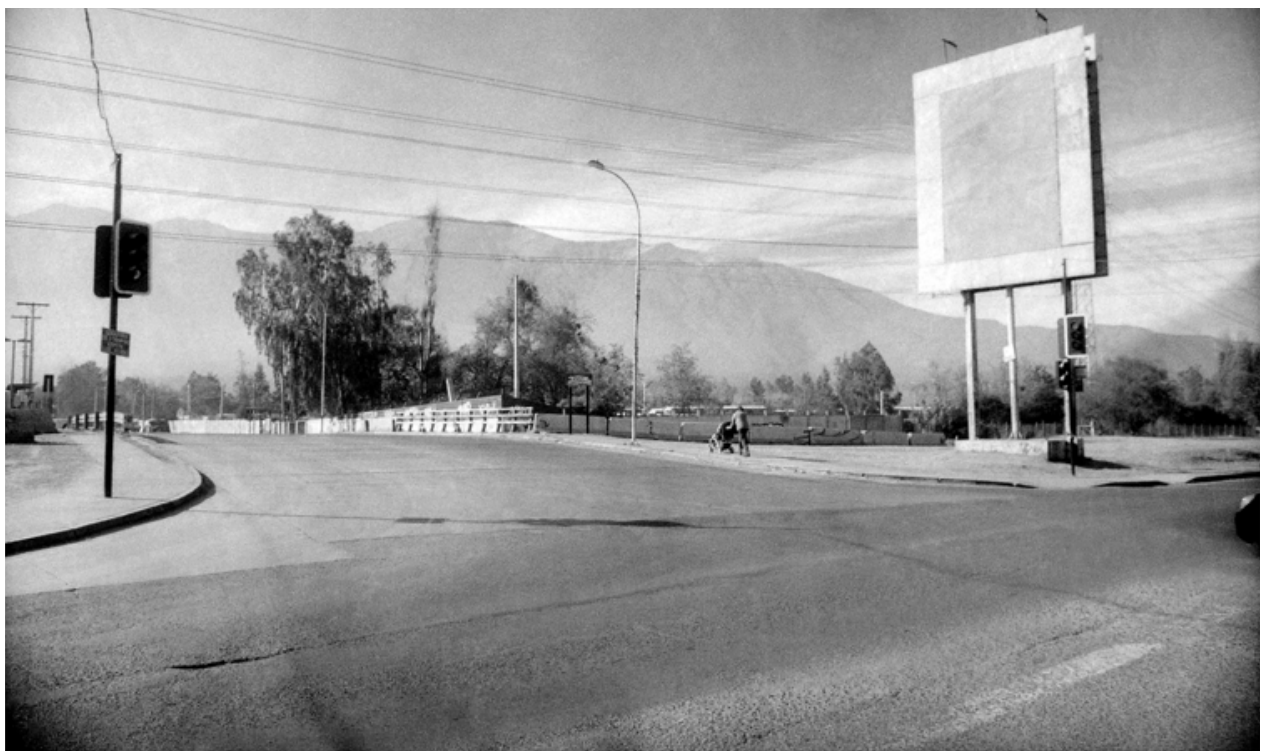

Francis Aedo Carrasco. Av. Palena 3387. La florida. 


\section{Cristian Kirby. Fotografía y desaparición}

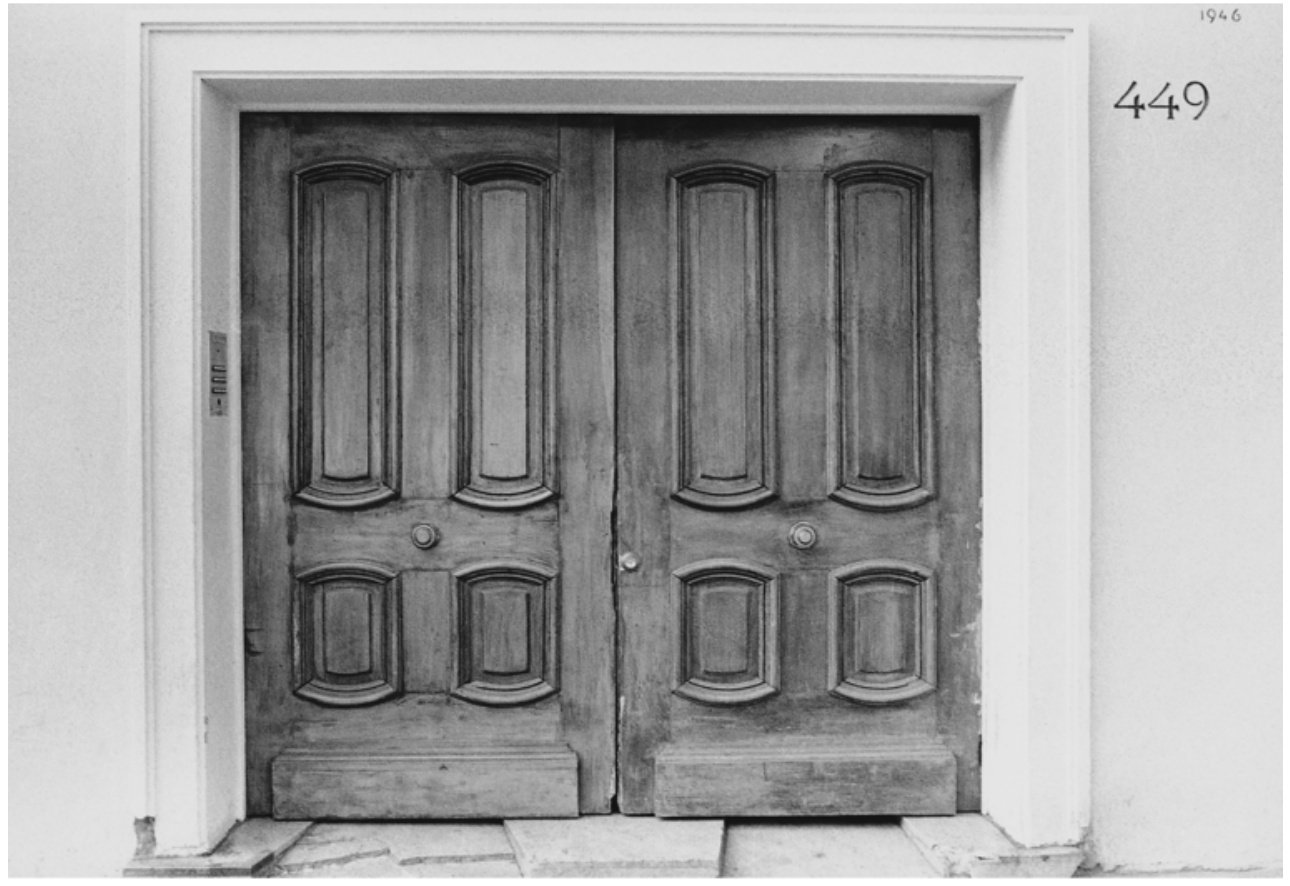

René Roberto Acuña Reyes. José Miguel de la Barra, 449.

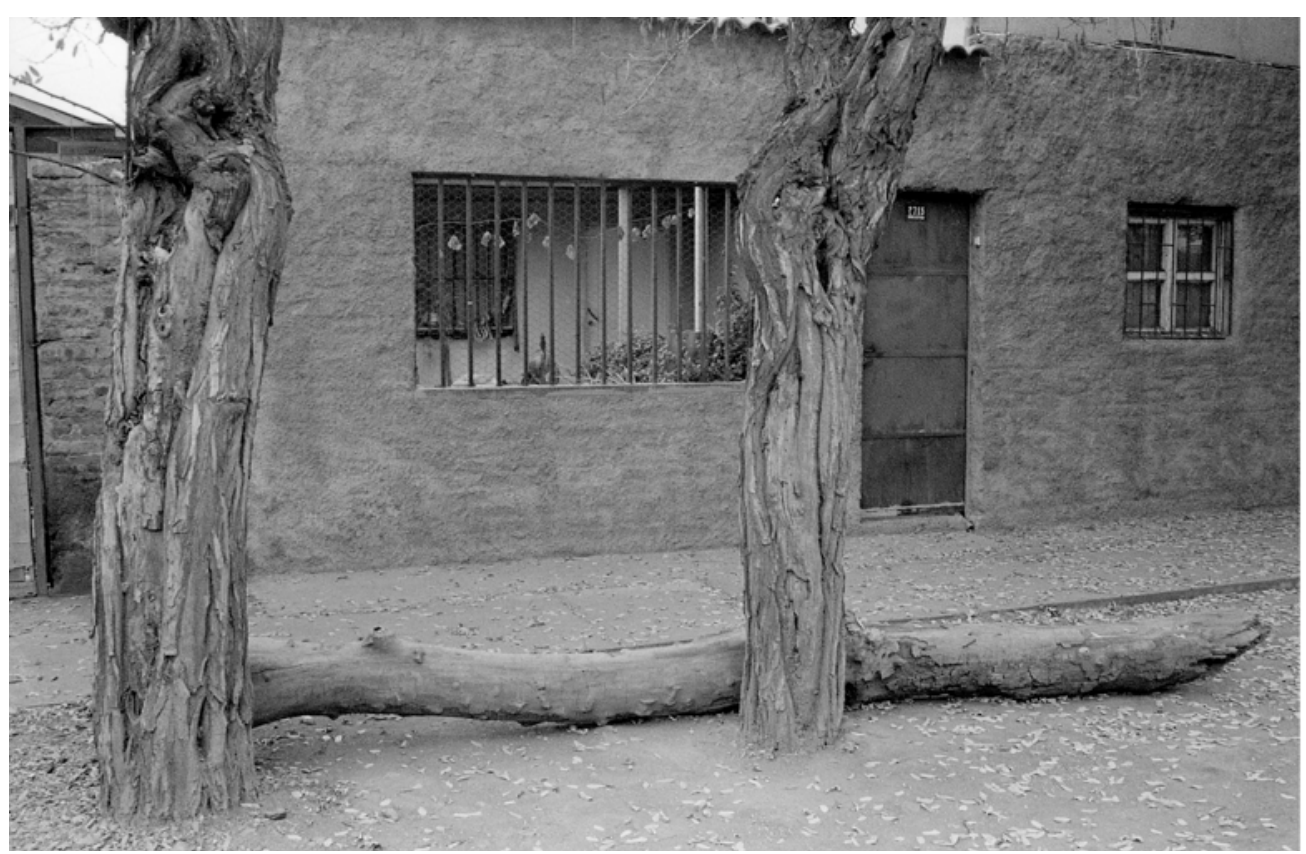

Miguel de Atero, 2715. Quinta Normal, Zacarías Machuca. 


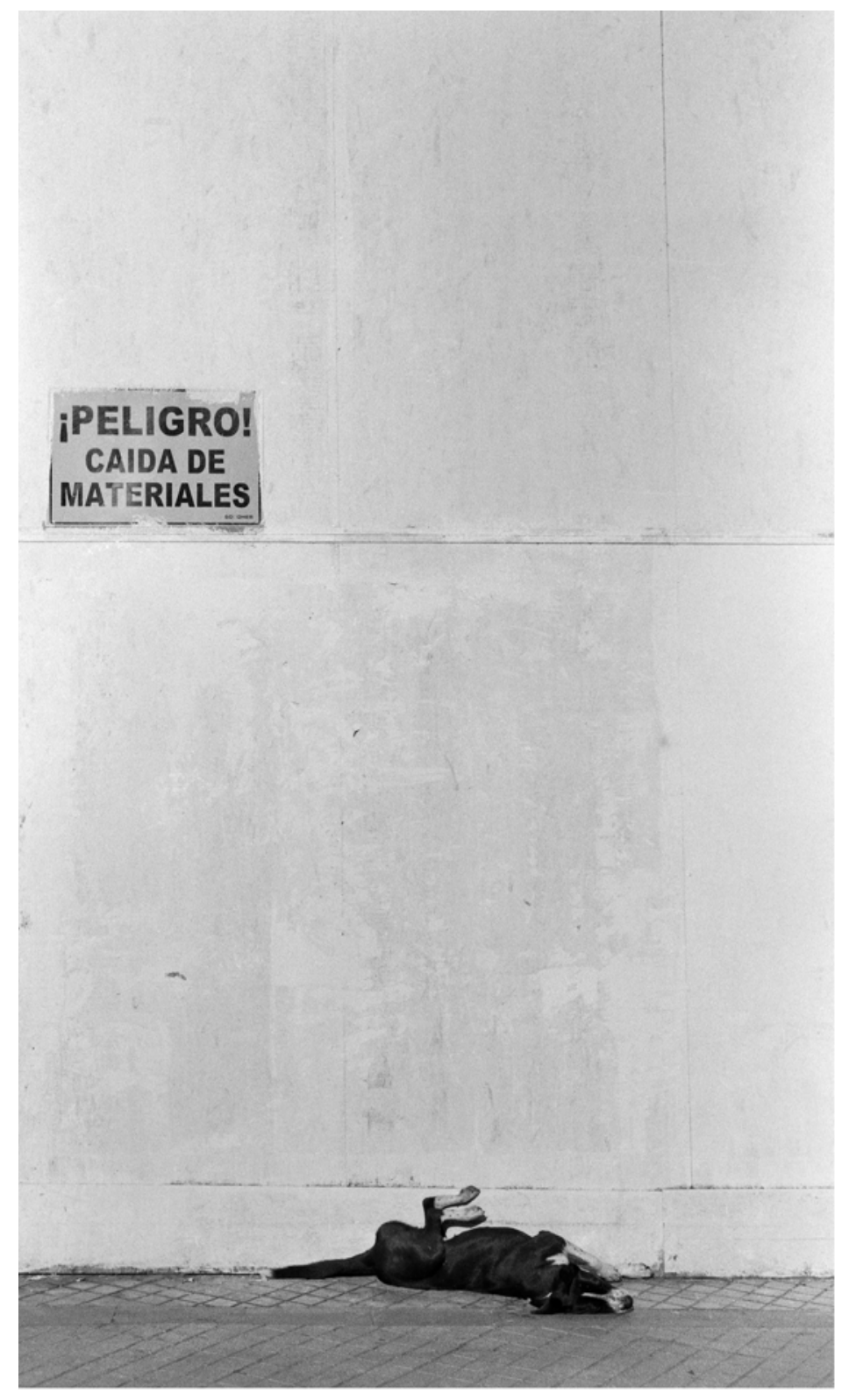

María Inés Alvarado Borgel. 


\section{9}
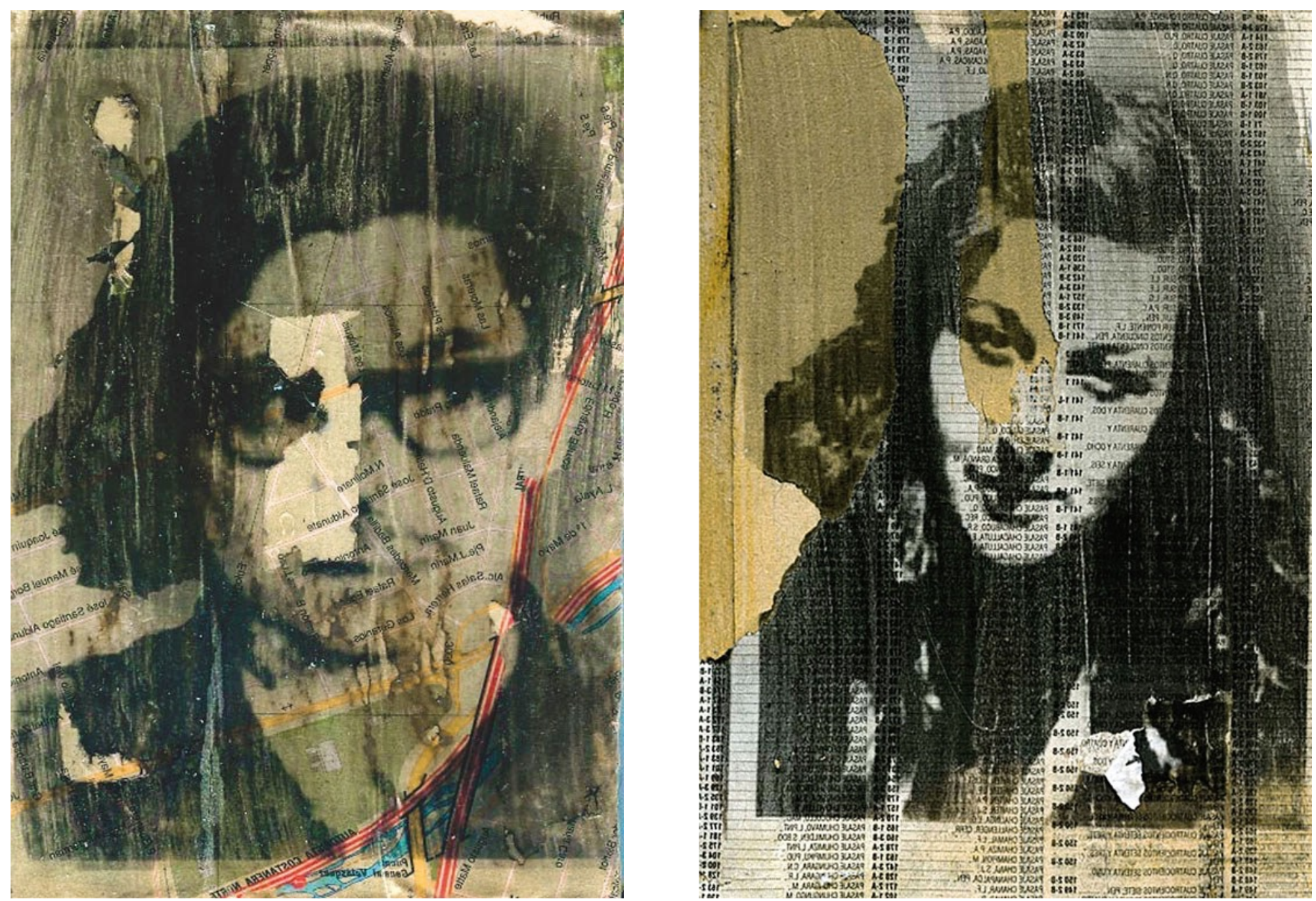

AVATARES DEL TESTIMONIO EN AMÉRICA LATINA

KAMCHATKA 6 DICIEMBRE 2015. PÁGS. 785-797 

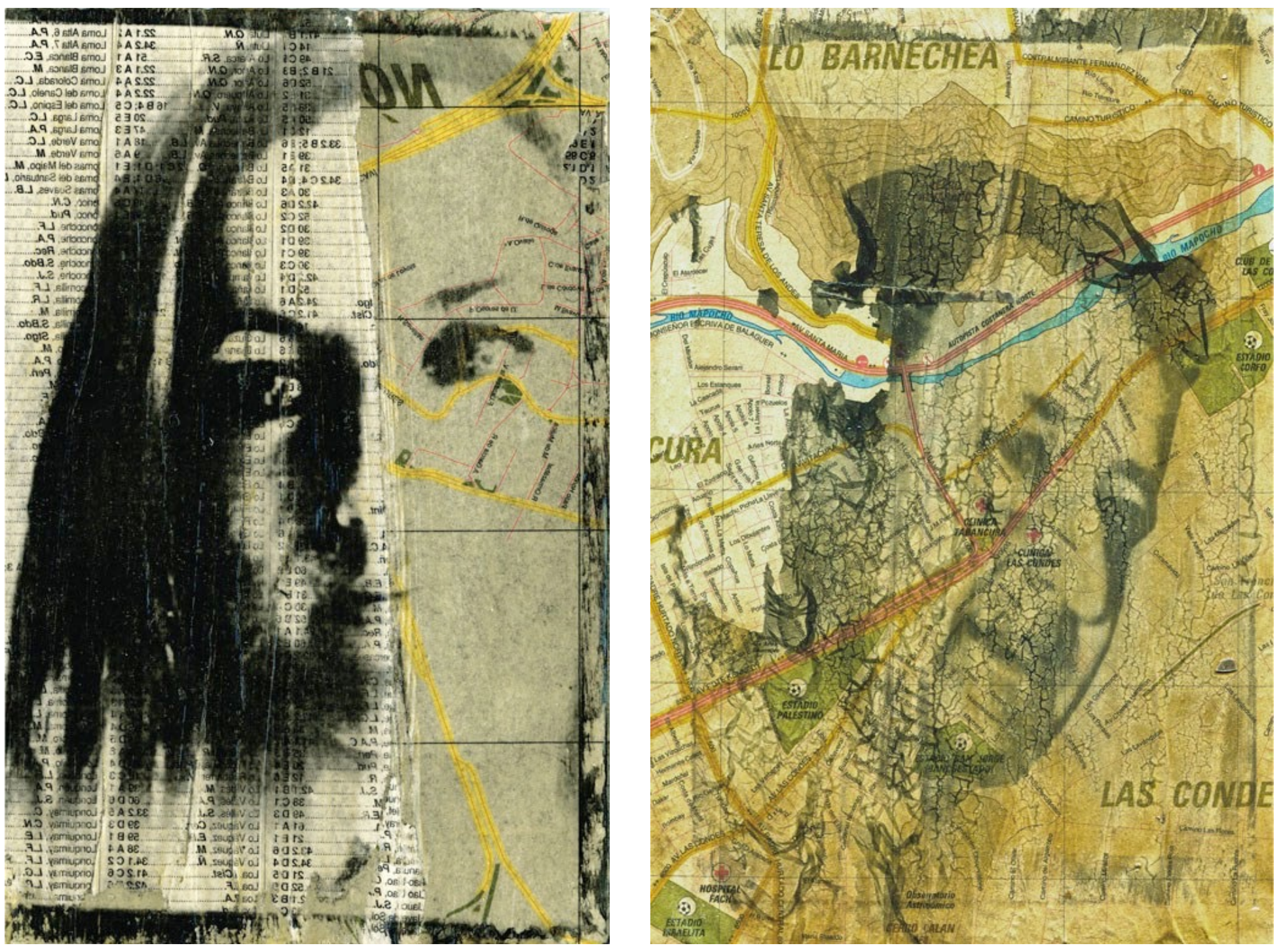

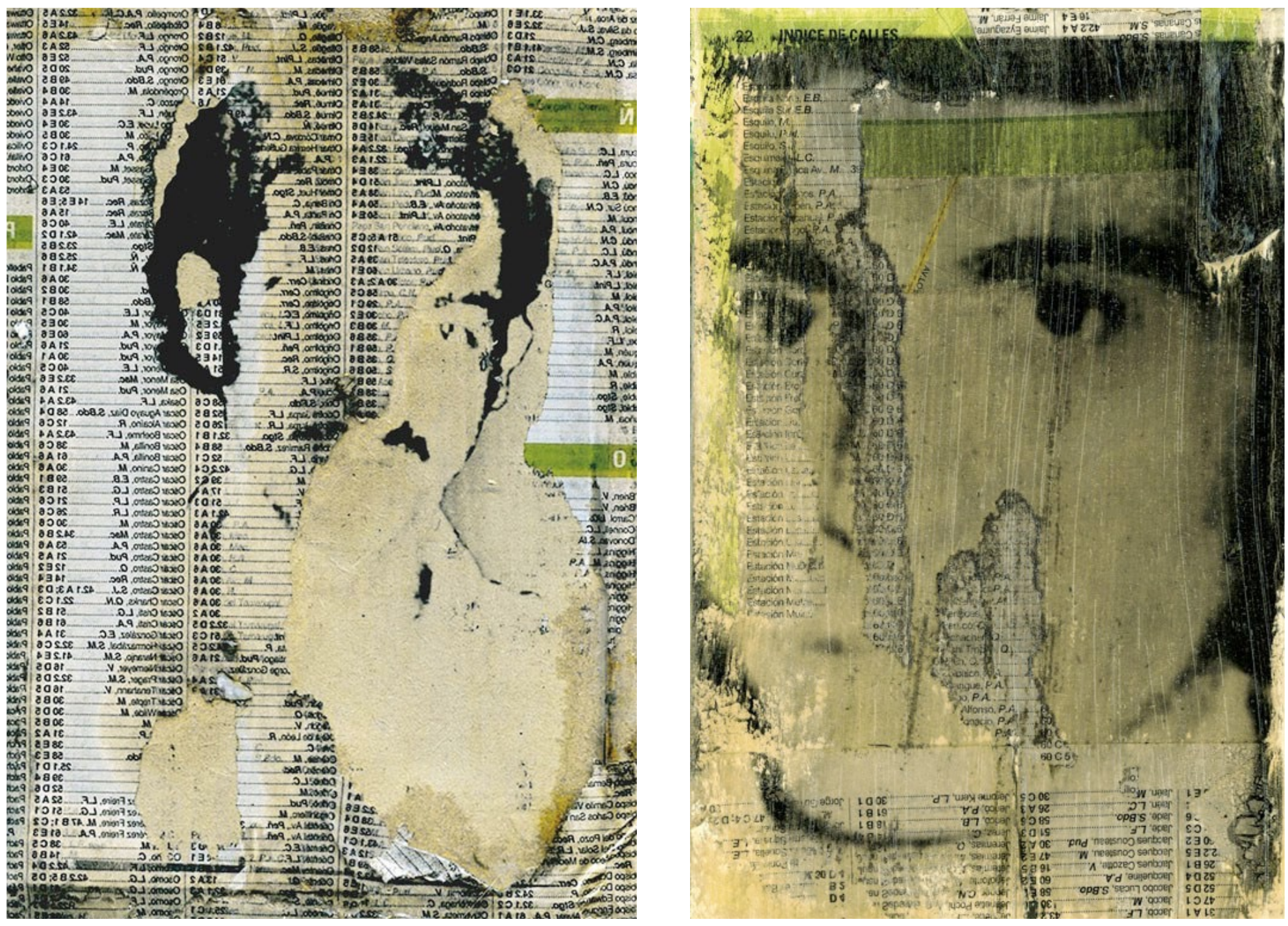

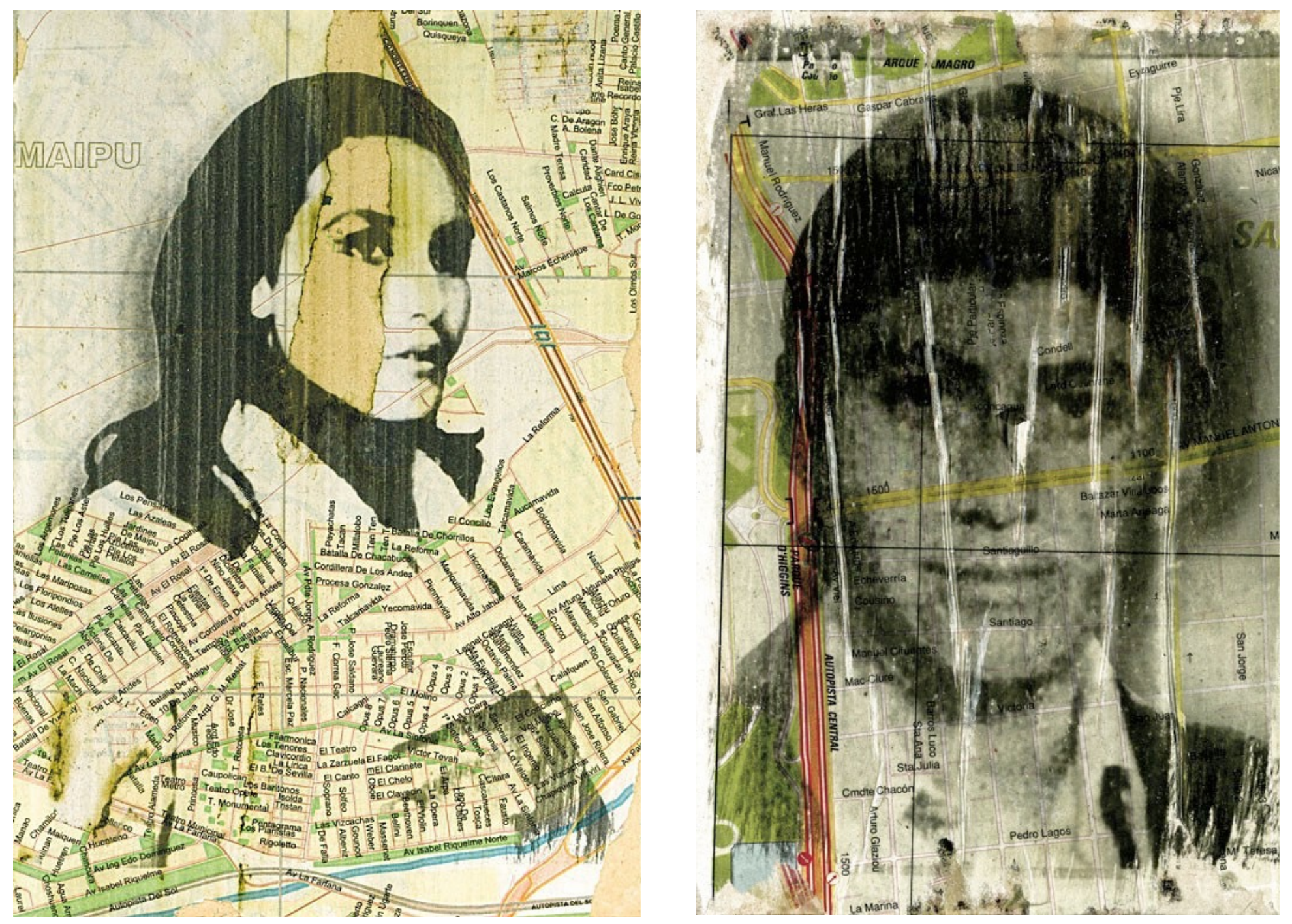


\section{Verdrangung/Reforest}

En el sistema trascendente de los árboles hay deformaciones anárquicas, raíces aéreas y tallos subterráneos.

Gilles Deleuze y Félix Guattari, Rhizome. 1977

Verdrangung/Reforest, es una serie de fotografías de árboles, que han sido plantados en acciones de reforestación. El proyecto busca generar una relación de sentido entre el modelo arbóreo y una estructura jerárquica que adhiere a un sistema de sentido vinculado a la idea de representación, y que propone un modelo unívoco y singular, a aquel que es sometido y controlado, en función de la integración al sistema, por medios coercitivos e institucionales que lo reproducen: familia/ escuela/estado-mercado.

Los “árboles" se ubican junto a un palo que los sostiene, endereza, guía en su desarrollo y a una malla que los protege. En este contexto lo fotográfico va a resaltar una situación de aislamiento, de fragilidad y precariedad de un paisaje en el descampado: el estado arbóreo se presenta como un modelo opuesto a un modelo rizomatico; que se realiza en lo orgánico y se manifiesta en lo múltiple. Sin embargo, este sistema surge de la tensión que lo desarticula: ramas, espigas, espinos y pasto seco. Cortes de aquello que emana, del paisaje: "un otro cualquiera no representado" que experimenta de manera sistemática: la erosión, el exterminio y también la persistencia como un acto resistencia, de voluntad y liberación. En este desplazamiento de lo ecológico a lo simbólico, lo arbóreo se constituye sobre las condiciones en que se "produce y re produce". 
Cristian Kirby. Fotografía y desaparición
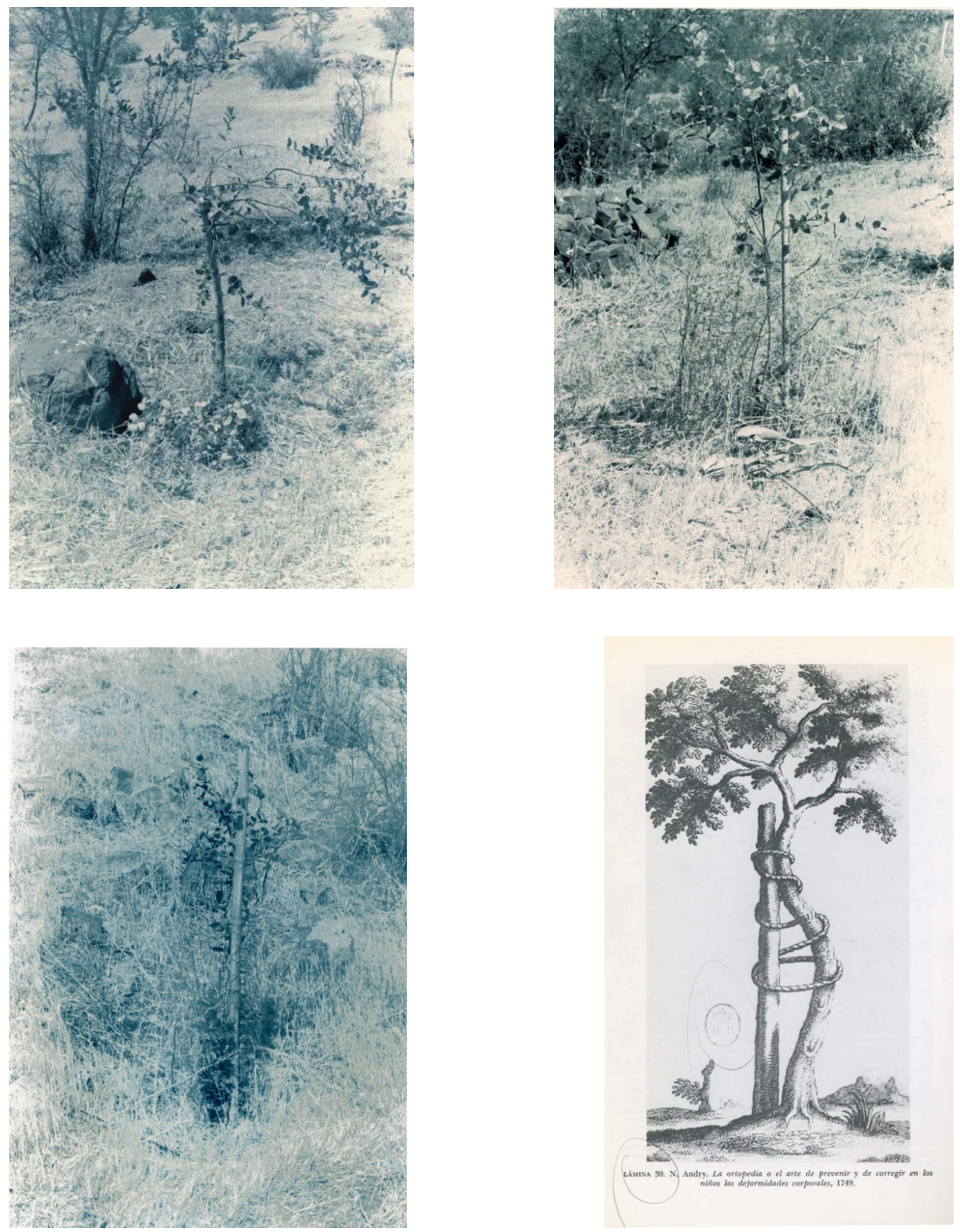

AVATARES DEL TESTIMONIO EN AMÉRICA LATINA

KAMCHATKA 6 DICIEMBRE 2015. PÁGS. 785-797 


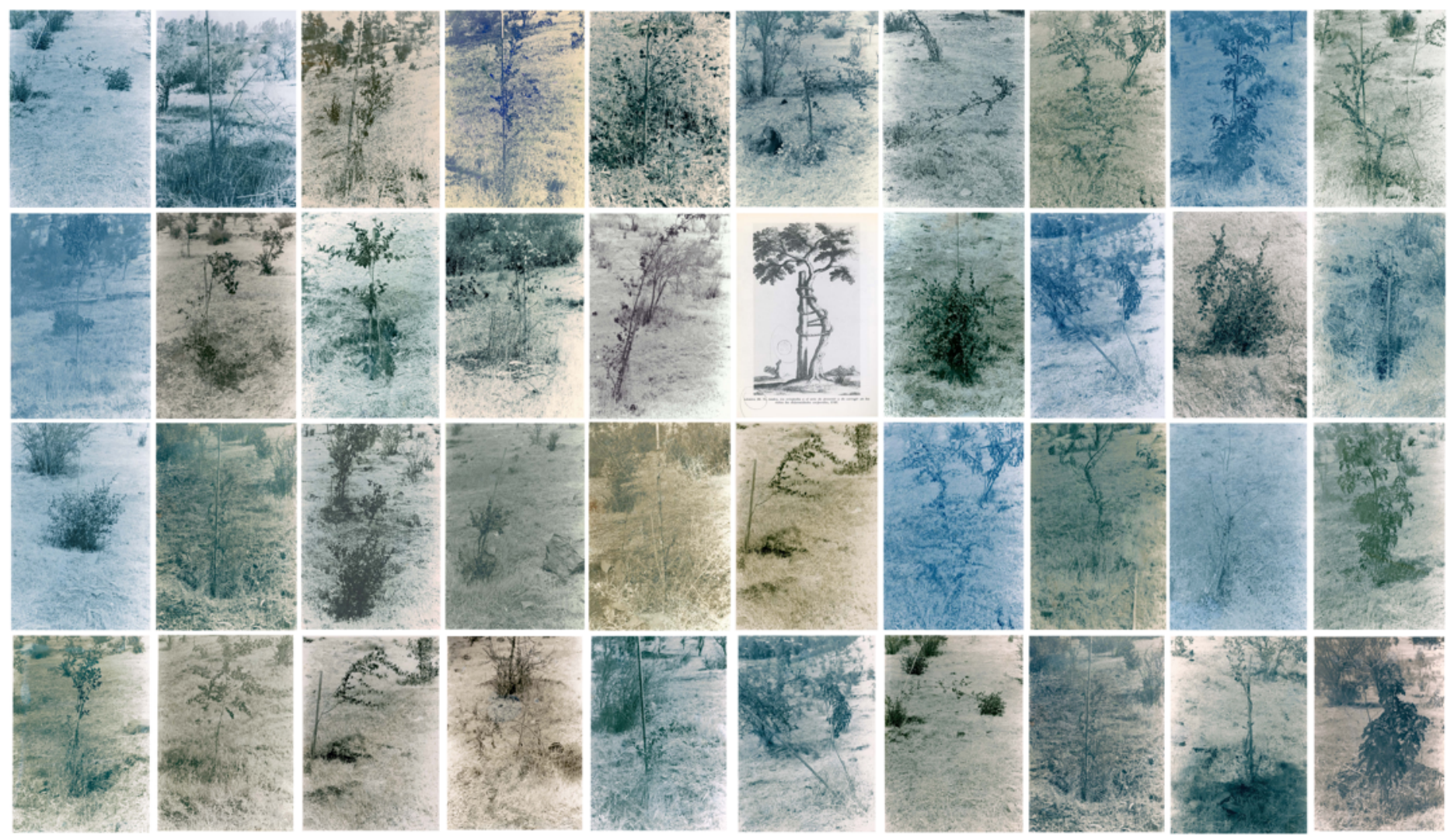

